\title{
Estimasi Populasi dan Karakteristik Habitat Lutung Jawa (Trachypithecus auratus) di Taman Hutan Raya R. Soerjo Jawa Timur
}

\author{
Estimation of Population and Characteristics of Java Labbit (Trachypithecus \\ Auratus) in Taman Hutan Raya R. Soerjo East Java \\ Andrie Ahlul Azmi ${ }^{*}$, Moch. Chanan², Nirmala Ayu Ariyanti ${ }^{2}$ \\ ${ }^{1}$ Mahasisawa Jurusan Kehutanan, Fakultas Pertanian-Peternakan Universitas Muhammadiyah \\ ${ }^{2}$ Fakultas Pertanian Peternakan, Universitas Muhammadiyah Malang \\ *Email : andrieazmi93@gmail.com
}

\begin{abstract}
Tahura R. Soerjo was declared a major forest area in 1992 which included protected forests of Mount Anjasmoro, Mount Gede, Mount Biru, Mount Limas, and the Arjuno-Lalijiwo nature reserve. In 1997, the area of $R$. Soerjo's great forest area increased to 27,868.30 hectares, which consisted of 22,908.3 hectares of protected forest, and the Arjuno-Lalijiwo Nature Reserve area of 4,960 hectares. Wild animals are animals that live in natural ecosystems. Wildlife is all animals that live in the wild that are not directly controlled or domesticated by humans. Wildlife management is the art of controlling wildlife habitat and population characteristics and human activities to achieve the desired goals. Wildlife management is part of wildlife conservation efforts.

Slim and long-tailed bodied Lutung. Hair color (hair) body varies depending on the species, from black and gray, to golden yellow. When compared to his legs, the Lutung's hands are fairly short, with their hairless soles. Lutung size ranges from 40-80 cm, weighing 5-15 kg; larger-bodied males than females. The protrusion above his eyes distinguishes Lutung from his close relative. The location of the observation is made systematically in the direction of the planned transect line. The point of observation is systematically intended to obtain varied data. By paying attention to the points that have been made in previous years. Based on the results obtained, it can be concluded that there are 3 highest types of INP plants from the tree level, namely Engelhardia spicata, Dampul Ficus lepicarpa, Quercus sundaicus Red Pairs. At the pole level there are Dampul Ficus lepicarpa, Berasan, Engukhardia spicat cucumber while at the sapling level there are Dampul Ficus lepicarpa, Put Buddleja asiantica, Put Red Quercus sundaicus. Each with an average value of 300.
\end{abstract}

Keywords: Population, Javan Lutung, Habitat Forest Park R. Soerjo, East Java.

\section{Inti Sari}

Tahura R. Soerjo dicanangkan sebagai kawasan hutan raya pada 1992 yang meliputi hutan lindung Gunung Anjasmoro, Gunung Gede, Gunung Biru, Gunung Limas, serta cagar alam ArjunoLalijiwo. Pada 1997, luas kawasan hutan raya R. Soerjo bertambah menjadi 27.868,30 hektare, yang terdiri dari 22.908,3 hektar hutan lindung, dan kawasan Cagar Alam Arjuno-Lalijiwo seluas 4.960 hektar. Satwa liar adalah binatang yang hidup di dalam ekosistem alam. Satwa liar merupakan semua hewan yang hidup di alam bebas yang tidak secara langsung dikontrol atau didomestifikasikan oleh manusia. Pengelolaan satwa liar merupakan seni dalam mengendalikan karakteristik habitat dan populasi satwa liar serta aktivitas manusia untuk mencapai tujuan yang diinginkan. Pengelolaan satwa liar merupakan bagian dari upaya konservasi satwa liar.

Lutung berbadan langsing dan berekor panjang. Warna bulu (rambut) tubuhnya berlainan tergantung spesiesnya, dari hitam dan kelabu, hingga kuning emas. Jika dibandingkan dengan kakinya, tangan lutung terbilang pendek, dengan telapak yang tidak berbulu. Ukuran lutung berkisar antara $40-80 \mathrm{~cm}$, dengan berat $5-15 \mathrm{~kg}$; pejantan berbadan lebih besar daripada betinanya. Tonjolan di atas matanya membedakan lutung dari saudara dekatnya, Lokasi pengamatan dibuat sistematik searah jalur transek yang telah direncanakan. Titik pengamatan tersebut dibuat secara sistematik dimaksudkan agar 
memperoleh data yang bervariatif. Dengan memperhatikan titik yang sudah pernah dibuat pada tahuntahun sebelumnya. Berdasarkan hasil yang di peroleh maka dapat di simpulkan bahwa terdapat 3 jenis tanaman INP tertinggi dari tingkat pohon yaitu Kukrup Engelhardia spicata, Dampul Ficus lepicarpa, Pasang Merah Quercus sundaicus. Pada tingkat tiang terdapat Dampul Ficus lepicarpa, Berasan, Kukrup Engelhardia spicat sedangkan pada tingkat pancang terdapat Dampul Ficus lepicarpa, Putihan Buddleja asiantica, Pasang Merah Quercus sundaicus. Masing-masing dengan rata-rata nilai 300.

Kata kunci : Populasi, Habitat, Lutung Jawa, Taman Hutan Raya R. Soerjo Jawa Timur.

\section{PENDAhUluAN}

Hutan rimba dihuni oleh binatang buas dan bertubuh kuat. Binatang yang bertahan hidup di hutan rimba adalah jenis binatang yang memiliki ketahanan hidup di hutan yang hanya ditumbuhi pohon besar dan kuat. Binatang yang mendiami hutan rimba sebagai habitatnya adalah hewan-hewan yang kuat seperti babi hutan, kera, gajah, macan kumbang, macan tutul, dan binatang kuat lainnya.

Tahura R. Soerjo dicanangkan sebagai kawasan hutan raya pada 1992 yang meliputi hutan lindung Gunung Anjasmoro, Gunung Gede, Gunung Biru, Gunung Limas, serta cagar alam Arjuno-Lalijiwo. Pada 1997, luas kawasan hutan raya R. Soerjo bertambah menjadi 27.868,30 hektare, yang terdiri dari 22.908,3 hektar hutan lindung, dan kawasan Cagar Alam ArjunoLalijiwo seluas 4.960 hektar.

Biasanya, Lutung beranak satu, dengan masa hamil tujuh bulan. Salah satu hal yang menarik dari monyet ini adalah anaknya yang berbulu keemasan, dan dipelihara oleh seluruh betina dalam kelompok. Seiring dengan bertambahnya umur, warna keemasan pada rambutnya ini akan semakin pudar berganti gelap hingga

\section{METODE PENELITIAN}

\section{Waktu dan Tempat Penelitian}

Penelitian ini dilaksanakan pada bulan Oktober 2018 sampai selesai, yang berlokasi didua wilayah yaitu, wilayah akhirnya mencapai dewasa pada umur 4-5 tahun. Hewan ini bisa hidup hingga 20 tahun.

Penelitian mengenai estimasi populasi dan karakteristik habitat Lutung Jawa (Trachypithecus auratus) perlu dilakukan, hal ini terkait dengan statusnya yang terancam punah, maka diadakan penelitian untuk mengestimasi populasi Lutung Jawa, serta keunikan habitat yang digunakan oleh suatu jenis satwa serta pengaruhnya terhadap populasi satwa yang menempati habitat tersebut. Taman Hutan Raya R. Soerjo merupakan salah satu habitat Lutung Jawa yang perlu diketahui data terkini terkait karakteristik habitat dan populasi Lutung Jawa mengingat semakin banyaknya ancaman terhadap kehidupan Lutung Jawa di kawasan taman hutan tersebut.

Keberadaan satwa liar di Indonesia saat ini hampir mendekati kepunahan. Salah satunya Lutung Jawa (Trachypithecus Auratus). Di Jawa Timur (Jatim), hal yang mendasari saya melakukan penelitian Lutung Jawa di Taman Hutan Raya R. Soerjo ( TAHURA) salah satunya karena keberadaan lutung jawa mulai terancam punah, akibat adanya konversi lahan dan pertanian

Cangar dan wilayah Coban Watu Ondo. Kedua wilayah tersebut masuk dalam kawasan Taman Hutan Raya R.Soerjo.

\section{Metode Pengambilan Data}

Lokasi pengamatan dibuat sistematik searah 
jalur transek yang telah direncanakan. Titik pengamatan tersebut dibuat secara sistematik dimaksudkan agar memperoleh data yang bervariatif. Dengan memperhatikan titik yang sudah pernah dibuat pada tahun-tahun sebelumnya. Datadata dan posisi pada peta dasar yang kurang meyakinkan (misalnya identifikasi tipe vegetasi yang meragukan) kemudian dilakukan pengecekan di lapangan sebagai bahan koreksi. Ground check dilakukan dengan metode line transect, data-data yang di butuhkan adalah jumlah individu dalam satu kelompok yang dijumpai serta mengamati perilaku lutung jawa, pengamatan dilakukan pada jalur transek dengan lebar plot yang telah di tentukan sebelumnya yaitu $20 \mathrm{~m}$. Setiap line transect memiliki panjang $1000 \mathrm{~m}$.

\section{HASIL DAN PEMBAHASAN}

\section{Gambaran Lokasi Penelitian}

Berdasarkan wilayah penelitian yang telah dilakukan di Taman Hutan Raya R Soerjo menggunakan line transek. Penelitian ini terbagi menjadi 5 jalur line transek, dimana jalur 1,2,3 dan 4 masuk kawasan wisata alam pemandian air panas Cangar wilayah Batu, dan di jalur 5 masuk kawasan wisata Coban Watu Ondo wilayah Mojoketo.

\section{Iklim dan Jenis Tanah}

Menurut klasifikasi iklim Schmid dan Ferguson Tahura R. Soerjo termasuk tipe iklim $C$ dan $D$ dengan curah hujan rata-rata $2.500-4.500 \mathrm{~mm}$ per tahun. Suhu udara di Taman Hutan Raya R. Soerjo berkisar antara 5 OC -10 OC. Jenis tanah yang terdapat di kawasan TAHURA R. Soerjo adalah jenis tanah regusol yang berbahan dasar abu pasir dan vulkanik intermaider, sehingga mudah tererosi. (UPT TAHURA R. Soerjo 2014).

\section{Karakteristik Lokasi Penelitian}

Kondisi vegetasi yang terdapat di wilayah pengambilan data (TAHURA R. Soerjo) memiliki karakteristik vegetasi yang berbeda-beda. Pada kawasan blok Cangar dengan luasan $25 \mathrm{Ha}$ dan blok Watu Omdo 14 Ha ssehingga total keseluruhan lokasi penelitian seluas $39 \mathrm{Ha}$, dengan pembagian jalur 1, 2, 3, dan 4 masuk pada blok Cangar dan jalur ke 5 masuk pada blok Watu Ondo. Pada blok Cangar tanaman yang mendominasi Kukrup (Engelhardia spicata) dan pada blok Watu Ondo di dominasi oleh jenis tanaman Pasang Merah (Lithocarpus elegans).

\section{Karakteristik Habitat Lutung Jawa di Taman Hutan Raya R.Soerjo}

Vegetasi tingkat semai ditemukan sebanyak 13 vegetasi yang di dominasi tanaman Berasan dan Putihan dengan masing-masing sebanyak 6 sampai 8 pohon.

vegetasi tingkat pancang di temukan sebanyak 19 jenis vegetasi yang di dominasi oleh 3 jenis vegetasi antara lain: Dampul, Putihan, Pasang Merah, yang memiliki nilai kerapatan masing-masingnya 0.0296, $0.0087,0.0191$ : dan INP masing-masing yakni $74.2758,52.6663,23.0426$.

vegetasi tingkat tiang di temukan sebanyak 20 jenis vegetasi yang di dominasi oleh 3 jenis vegetasi antara lain: Dampul, Berasan, Kukrup, yang memiliki nilai kerapatan masing-masingnya $0.0065,0.0048,0.0052$ : dan INP masing-masing yakni 41.2311,

\begin{tabular}{|l|l|l|l|}
\hline NO & Individu(Ekor) & $\begin{array}{l}\text { Kepadatan } \\
\text { Populasi(Ekor/Ha) }\end{array}$ & $\begin{array}{l}\text { Estimasi } \\
\text { Populasi } \\
\text { (Ekor) }\end{array}$ \\
\hline 1 & 8 & 0,0004 & 3,466 \\
\hline
\end{tabular}

$30.2365,28.4085$.

vegetasi tingkat pohon di temukan sebanyak 19 jenis vegetasi yang di dominasi oleh 3 jenis vegetasi antara lain: Kukrup Engelhardia spicata, Dampul Ficus lepicarpa, Pasang Merah Quercus 
sundaicus, yang memiliki nilai kerapatan masing-masingnya 0.0037, 0.0028, 0.0016: dan INP (Indeks Nilai Penting) masingmasing yakni 52.0346, 41.4939, 29.4648.

\section{Estimasi Populasi Lutung Jawa (Trachypithecus auratus) di Taman Hutan Raya R. Soerjo}

Berdasarkan perhitungan pendugaan populasi melalui metode transek garis yang dilakukan dengan mengaplikasikan persamaan king's method sebagai berikut:

$\mathrm{d}=\mathrm{N} / 2(\mathrm{XD})$ dan $\mathrm{EP}=\mathrm{NA} / \mathrm{Q}$

Keterangan simbol-simbol rumus yang digunakan:

$\mathrm{d}=$ Densitas

$\mathrm{N}$ = Total individu yang terdeteksi saat pengamatan

$X=$ Panjang jalur

$\mathrm{D}=$ Jarak antara primata target saat pertama kali terdeteksi observer (rataan)

$\mathrm{A}=$ Luas total kawasan pengamatan

$\mathrm{Q}=$ Luas sampel pengamatan

$\mathrm{EP}=$ Estimasi ukuran populasi

Tabel.1 Kawasan jalur satu pemandian air panas Cangar

Berdasarkan analisis data Kawasan jalur pertama pemandian air panas Cangar maka dapat di ketahui dugaan Kepadatan Populasi 0,0017 dengan Estimasi Populasi 26,520 individu luasan areal $25 \mathrm{Ha}$

Tabel.2 Kawasan jalur dua pemandian air panas Cangar

Berdasarkan analisis data Kawasan jalur dua pemandian air panas Cangar maka dapat di ketahui dugaan Kepadatan Populasi 0,0004 dengan Estimasi Populasi 3,466 individu luasasn areal $25 \mathrm{Ha}$

Tabel.3 Kawasan jalur tiga pemandian air panas Cangar

\begin{tabular}{|l|l|l|}
\hline NO & $\begin{array}{l}\text { Individu } \\
\text { (Ekor) }\end{array}$ & $\begin{array}{l}\text { Kepadatan } \\
\text { Populasi(Ekor/Ha) }\end{array}$ \\
\hline
\end{tabular}

\begin{tabular}{|l|l|l|l|}
\hline 1 & 4 & 0,0002 & 3,900 \\
\hline
\end{tabular}

Berdasarkan analisis data Kawasan jalur tiga pemandian air panas Cangar maka dapat di ketahui dugaan Kepadatan Populasi 0,0002dengan Estimasi Populasi 3,900 individu luasasn areal $25 \mathrm{Ha}$

Tabel.4 Kawasan jalur empat pemandian air panas Cangar

\begin{tabular}{|l|l|l|l|}
\hline NO & Individu(Ekor) & $\begin{array}{l}\text { Kepadatan } \\
\text { Populasi(Ekor/ } \\
\mathrm{Ha})\end{array}$ & $\begin{array}{l}\text { Estimasi } \\
\text { Populasi } \\
\text { (Ekor) }\end{array}$ \\
\hline 1 & 9 & 0,0004 & 7,020 \\
\hline
\end{tabular}

Berdasarkan analisis data Kawasan jalur empat pemandian air panas Cangar maka dapat di ketahui dugaan Kepadatan Populasi 0,0004 dengan Estimasi Populasi 7,020 individu luasasn areal $25 \mathrm{Ha}$

Tabel.5 Kawasan jalur lima wilayah Coban Watu Ondo

\begin{tabular}{|l|l|l|l|}
\hline NO & $\begin{array}{l}\text { Individu } \\
\text { (Ekor) }\end{array}$ & $\begin{array}{l}\text { Kepadatan } \\
\text { Populasi(Ekor/Ha) }\end{array}$ & $\begin{array}{l}\text { Estimasi } \\
\text { Populasi } \\
\text { (Ekor) }\end{array}$ \\
\hline 1 & 10 & 0,001 & 15,600 \\
\hline
\end{tabular}
Berdasarkan analisis data Kawasan jalur lima pemandian air panas Cangar maka dapat di ketahui dugaan Kepadatan Populasi 0,001 dengan Estimasi Populasi 15,600 individu luasasn areal $14 \mathrm{Ha}$ Melalui table di atas dapat diketahui jumlah

\begin{tabular}{|l|l|l|l|}
\hline NO & Individu(Ekor) & $\begin{array}{l}\text { Kepadatan } \\
\text { Populasi(Ekor/Ha) }\end{array}$ & $\begin{array}{l}\text { Estimasi } \\
\text { Populasi } \\
\text { (Ekor) }\end{array}$ \\
\hline & & & \\
\hline 1 & 17 & 0,0017 & 26,520 \\
\hline
\end{tabular}

keseluruhan dugaan populasi Lutung Jawa (Trachypithecus auratus) pada kawasan Taman Hutan Raya R. Soerjo, yang terdiri dari 2 kawasan dengan masing masing kawasan memiliki hasil dugaan Estimasi Populasinya berjumlah 26,520 ; 3,466 ; 3,$900 ; 7,020 ; 15,600$

sehingga di peroleh total dugaan Estimasi

Populasi Lutung Jawa (Trachypithecus auratus) dari kedua wilayah Taman Hutan Estimasi alya R. Soerjo, berjumlah 56,506 individu.

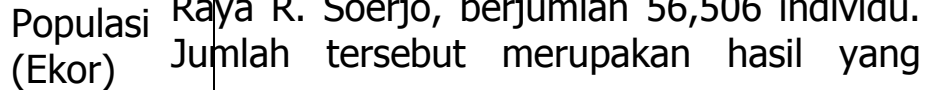


relative kecil jika dilihat dari luas keseluruhan Taman Hutan Raya R. Soerjo, Hal tersebut di karenakan pada saat pengambilan data cuaca dan kondisi lapang kurang mendukung.

Nilai kepadatan populsai Lutung Jawa sedikit banyaknya di pengaruhi oleh jumlah perjumpaan terhadap Lutung Jawa. Pada setiap daerah, persebaran Lutung Jawa di Pulau Jawa memiliki tingkat intensitas perjumpaan yang berbeda-beda pada tiaptiap Daerah. Perbedaan ini disebabkan oleh beberapa factor lokasi penelitian, ketinggian, metode penelitian,tipe habitat, serta durasi lama waktu penelitian.. lamanya waktu penelitian ini tergolong singkat ya itu selama 30 hari, sehingga hasil perjumpaan dengn Lutung Jawa tidak terlalu optimal.

Perjumpaan Lutung Jawa dari kelima Jalur lebih banyak dijumpai pada jalur kawasan Pemandian Air Panas Cangar, karena banyaknya ketersediaan pasokan makanan di sekitaran kaki gunung Arjuna selain itu jugak wisatawan yang memberi makan secara langsung sehingga Lutung jawa tersebut terbiasa dan berani terhadap pengunjun di area Pemandian Air Panas Cangar.

\section{PENUTUP}

\section{KESIMPULAN}

Berdasarkan dari analisis data serta pembahasan dari hasil penelitian status Estimasi Populasi dan Karakteristik Habitat Lutung Jawa Trachypithecus auratus di Taman Hutan Raya R. Soerjo Jawa Timur. Dapat disimpulkan sebagai berikut :

Dari jumlah total keseluruhan luasan penelitian terdapat 56,506 individu/ hektar. Terdapat 3 jenis tanaman yang memiliki nilai INP tertinggi di mulai dari tingkat pohon yaitu Kukrup Engelhardia spicata, Dampul Ficus lepicarpa, Pasang Merah Quercus sundaicus. Pada tingkat tiang terdapat Dampul Ficus lepicarpa, Berasan, Kukrup Engelhardia spicat sedangkan pada tingkat pancang terdapat Dampul Ficus lepicarpa, Putihan Buddleja asiantica, Pasang Merah Quercus sundaicus. Total nilai INP pada tiap tingkatan memiliki nilai INP 300 yanag menunjukan bahwa masih layak untuk di tempati Lutung Jawa.

\section{DAFTAR PUSTAKA}

Alamendah. 2010. Lutung Jawa (Trachypithecus auratus). https://alamendah.org/2010/07/13/l utung-jawa-trachypithecus-auratus/

Alikodra HS. 2002. Pengelolaan Satwa Liar Jilid 1. Bogor: Yayasan Penerbit Fakultas Kehutanan IPB.

Ambarwati R. 1999. Studi perbandingan perilaku lutung hitam (Trachypithecus auratus) di kebun binatang dan taman nasional baluran [skripsi]. Surabaya (ID): Jurusan Biologi FMIPA Universitas Airlangga.

Anonymouse. 2014. Peraturan Mentri Kehutanan Repubik Indonesia. (Online) http://www.dephut.go.iddiakses 5 Agustus 2018

Ayunin Q. 2013. Seleksi habitat Lutung Jawa (Trachypithecus auratus Sains \& Entrepreneurship IV cristatus) di Taman Nasional Gunung Merapi. [tesis]. Yogyakarta [ID]: Universitas Gadjah Mada.

Betrand M. 1969. The Behavioral Repertoir of Stumptail Macaque. Switzerland: Karger Basel.

Brandon-Jones D. 1995. A revision of the asian pied leaf-monkeys (Mammalia: Cercopithecidae: Superspecies Semnopithecus auratus), with a 
description of a new subspecies. Raff Bull Zool. 43:3-43.

Cannon W, Vos A. 2009. "Trachypithecus auratus" (On-line), animal diversity web.

http://animaldiversity.ummz.umich.e du/site/accounts/information/Trachy pithecus_auratus.html.

Chiver DJ, Raemakers JJ. 1980. Malayan Forest Primates. New York: Plenum Press.

Forest Watch Indonesia (FHI). 2009. Potret keadaan hutan Indonesia periode 2000-2009.

Groves CP. 2001. Primate Taxonomy. Washington DC (US): Smithsonian Institute Press.

Gurmaya KJ, Adiputra IMW, Saryatiman AB, Danardono SN, Sibuea TTH. 1994. A preliminary study on ecology and conservation of the java primates in Ujung Kulon National Park, West Java, Indonesia. In: Thierry $\mathrm{B}$, Anderson JR, Roeder JJ, Herrenschmidt $\mathrm{N}$ (ed). Current Primatology. Strasbourg (FR): Universite Louis Pasteur.

Indonesian Forest. 2015. Taman Hutan Raya Raden Suryo. Jawa Timur. http://forestid.blogspot.com/2015/1 1/taman-hutan-raya-r-suryo-jawatimur.html

Irwanto. 2006. Focused Group Discussion (FGD) : Sebuah Pengantar Praktis. Yayasan OborIndonesia. Jakarta.

[IUCN] International Union for Corservation of Nature and Natural Resources. 2008. Trachypithecus auratus. http://www.iucnredlist.org/apps/redl ist/details/22034/0

Isabirye B,M Gilbert and SL Jeremiah. 2008. Primate population and their interaction with changing habitat.
International Journal of Primatology 29, 35-48.

Muchlisin Riadi. 2012. Jawa Timur (Online). https://www.kajianpustaka.com 2012/12/ klasifikasi-biomorfologidan-ekologi.html (Di akses pada tanggal 22 Agustus 2018).

Nadler T, Momberg F, Dang NX, Lormee N. 2002. Leaf monkeys. Vietnam Primates Conservation Review-Part 2. http://www.fauna-flora.org.

Newsome D,D Ross and M Susan. 2005. Wildlife Tourism Aspects of Tourism. 152. Channel View Publications. Clevedon. Buffalo. Toronto.

Nijman V, van Balen. 1998. A faunal survey of The Dieng Mountains, Central Java, Indonesia: distribution and conservation of endemic primate taxa. Oryx 32(2):145-156.

Nijman V. 2000. Geographic distribution of ebony leaf monkey Trachypithecus auratus (E. Geoffroy Saint-Hilaire, 1812) (Mammalia: Primates: Cercopithecidae). Contr. Zool. 69(3):157-177.

Nisa Syachera Febriyanti, 2008. Studi Karakteristik Cover Lutung Jawa (Trachypithecus Auratus Geoffroy 1812) Di Blok Ireng-Ireng Taman Nasional Bromo Tengger Semeru Jawa Timur. IPB. Jawa Barat

Pratiwi AN. 2008. Aktivitas pola makan dan pemilihan pakan pada lutung kelabu betina (Trachypithecus cristatus, raffles 1812) di Pusat Penyelamatan Satwa Gadog Ciawi - Bogor [skripsi]. Bogor (ID): Program Studi Ilmu Nutrisi dan Makanan Ternak Fakultas Peternakan IPB.

Profauna. 2010. Profauna press release 26 Novenber $2010 \quad$ [internet. http://www.profauna. org. 
Profauna Indonesia. 2013. Lutung Jawa. http://www.google.com/LutungJawa-di-Pasar-Jawa-Timur/

SK. Menteri Kehutanan dan Perkebunan No. 773/Kpts-II/1999.

Sofial M. 2014. Perburuan liar, populasi lutung jawa tinggal $30 \%$. Bisnis Indonesia. Rubrik Lintas Jagat: 4 (kol 3-7).

Sulistiyadi, Eko. 2013. Perilaku lutung jawa Trachypithecus Auratus (E. Geoffroy, 1812) pada fragmen habitat terisolasi di TWA Gunung Pancar. Sekolah Pascasarjana Institut Pertanian Bogor.

Supriatna dan Edy, 2000. Panduan Lapangan Primata Indonesia.
Yayasan Pustaka Obor Indonesia. Jakarta

Wisnu Sinartejo. 2013. Jawa Timur (Online) Kajian Terhadap Lutung Jawa (Trachypithecus auratus). http://maxgeografi.blogspot.com/20 13/02/kajian-terhadap-hewanlutung-jawa 1815.html. (Di akses pada tanggal 22 Agustus 2018)

Zainal FD. 2008. Perbandingan aktivitas harian lutung jawa di Pusat Pelestarian Satwa (PPS) Petungsewu dan Suaka Margasatwa Dataran Tinggi Hyang [skripsi]. Malang (ID): Jurusan Biologi Fakultas Sains dan Teknologi UIN Malang. 